\title{
Pendidikan Nilai Religius pada Novel Sandiwara Langit Karya Abu Umar Basyier
}

\author{
Megi Afroka ${ }^{1}$ \\ ${ }^{1}$ Prodi Manajemen Informatika, AMIK Kosgoro \\ JI. RSDK No. 340 Koto Panjang Kota Solok 27312 \\ * Corresponding Author. E-mail: ${ }^{1}$ afrokamegi@gmail.com
}

\begin{tabular}{|l|l|l|}
\hline Receive: $12 / 09 / 2020$ & Accepted: 02/10/2020 & Published: 04/10/2020 \\
\hline
\end{tabular}

\begin{abstract}
Abstrak
Sastra merupakan hasil karya dari pikiran manusia. Kehadiran sastra di tengah peradaban manusia tidak dapat ditolak, bahkan kehadirannya diterima sebagai salah satu realitas sosial budaya. Contoh dari karya sastra tersebut adalah novel. Novel adalah karangan prosa panjang yang mengandung rangkaian cerita kehidupan seseorang dengan orang yang berada di sekelilingnya dengan menonjolkan watak dan sifat dari setiap pelaku dalam kisah yang diceritakan. Dalam novel ada unsur yang membangun yaitu unsur intrinsik dan ekstrinsik, unsur ekstrinsik adalah unsur yang membangun dari luar yang terdiri dari nilai-nilai, nilai religius merupakan nilai yang selalu berhubungan dengan Tuhan, dalam novel Sandiwara Langit banyak ditemukan nilai religius dari tokoh Rizqaan, Rizqaan dalam kehidupan sehari-hari selalu beribadah menurut agama dan kepercayaanNya.
\end{abstract}

Kata kunci: sastra, novel, nilai religius

\begin{abstract}
Literature is the work of the human mind. The presence of literature in the midst of human civilization cannot be denied, even its presence is accepted as one of the socio-cultural realities. Examples of literary are novels, a novel is a long prose composition containing a series of stories of a person's life by highlighting the character and nature of each actor in the story being told. Novels have constructive elements namely intrinsic and extrinsic elements, extrinsic elements are elements that construct from the outside which consist of values, religious value are values always related to god, in the "Sandiwara Langit" there are many religious values of Rizqaan figures, Rizqaan in every day life always worship according to religion and belief.
\end{abstract}

Keywords: literature, novel, religious value

\section{PENDAHULUAN}

Sastra merupakan salah satu cabang ilmu pengetahuan yang selalu ada alam peradaban manusia semenjak ribuan tahun yang lalu. Kehadiran sastra di tengah peradaban manusia tidak dapat ditolak, bahkan kehadirannya diterima sebagai salah satu realitas sosial budaya. Hingga saat ini sastra tidak saja dinilai sebagai sebuah karya seni yang memiliki budi, imajinasi, dan emosi, tetapi telah dianggap sebagai suatu karya kreatif yang dimanfaatkan sebagai konsumsi intelektual di samping konsumsi emosi[1].
Salah satu bentuk karya sastra adalah novel. Novel adalah karya fiksi yang dibangun melalui berbagai unsur baik unsurintrinsikmaupun unsur ekstrinsiknya[2]. Unsur tersebut sengaja dipadukan pengarang dan dibuat mirip dengan dunia nyata lengkap dengan peristiwa-peristiwa di dalamnya, sehingga tampak seperti sungguh ada terjadi. Unsur inilah yang menyebabkan karya ada. Selain unsur intrinsik juga ada unsur ekstrinsik. Unsur ekstrinsik merupakan unsur yang berasal dari luar karya sastra itu sendiri. Novel yang akan dijadikan 
jurnal adalah Novel Sandiwara Langit karya Abu Umar Basyier cetakan kesepuluh.

Unsur novel yang akan dibahas pada artikel ini adalah unsur ekstrinsik. Unsur ekstrinsik adalah unsur yang ada di luar novel, dimana secara tidak langsung unsur ekstrinsik mempengaruhi proses pembuatan sebuah novel, berikut unsur ekstrinsik dalam novel:

1. Latar belakang masyarakat

1. Latar belakang masyarakat adalah hal yang mendasari seorang penulis membuat sebuah novel yang mana menyangkut kondisi lingkungan masyarakat. Ada beberapa faktor yang dapat mempengaruhi penulis antara lain:
a. Ideologi Negara
b. Kondisi politik
c. Kondisi sosial
d. Kondisi ekonomi

2. Latar belakang penulis

2. Latar belakang penulis adalah faktor yang ada dalam diri penulis sehingga mendorong penulis dalam membuat sebuah novel. Ada beberapa faktor latar belakng antara lain:
a. Riwayat hidup penulis
b. Kondisi psikologis
c. Aliran sastra penulis

3. Nilai-nilai yang terkandung dalam novel meliputi:

a. Nilai religius atau agama

b. Nilai sosial

c. Nilai moral

d. Nilai budaya

Dari beberapa penjabaran di atas, penulis mengambil nilai religius, nilai religius merupakan nilai yang berhubungan langsung dengan Tuhan, dengan adanya nilai religius pada Novel Sandiwara Langit diharapkan kepada pembaca dapat memahami lebih mendalam tentang nilai religius yang bisa diterapkan dalam kehidupan sehari-hari.

\section{METODE}

Bahan yang digunakan dalam penelitian adalah Novel Sandiwara Langit karya Abu Umar Basyier cetakan kesepuluh, metode yang digunakan adalah metode kualitatif. Penelitian kualitatif adalah penelitian yang bertujuan untuk memahami gejala mengenai apa yang diperoleh subjek penelitian, seperti perilaku, persepsi, motivasi dan tindakan secara holistic dan dengan cara deskripsi dalam bentuk kata-kata dan bahasa, pada suatu konteks khusus yang alamiah dan dengan memanfaatkan beraneka macam metode alamiah.

Penelitian kualitatif adalah suatu penelitian ilmiah yang bertujuan memahami suatu fenomena dalam konteks sosial secara alamiah dengan mengedepankan proses interaksi yang mendalam antara peneliti dengan fenomena yang diteliti.[3]

Ciri-ciri penelitian kualitatif:

1. Lingkungan alamiah sebagai sumber data langsung.

2. Manusia merupakan instrumen utama pengumpulan data.

3. Analisis data dilakukan secara induktif.

4. Penelitian bersifat deskriptif analitif (data berupa kata-kata, gambar, dan perilaku) tidak dituangkan dalam bentuk bilangan atau angka statistik.

5. Tekanan penelitian berupa proses, penelitian kualitatif lebih banyak mementingkan segi proses daripada hasil.

6. Pembatasan penelitian berdasarkan fokus.

7. Perencanaan bersifat lentur dan terbuka.

8. Pendekatan penelitian menggunakan metode kualitatif.

9. Penelitian bersifat menyeluruh (holistik).

Tujuan penelitian kualitatif adalah untuk memahami (to understand) fenomena atau gejala sosial dengan lebih menitikberatkan pada gambaran yang lengkap tentang fenomena yang dikaji daripada memerincinya menjadi variabelvariabel yang saling terkait[4]. Harapannya adalah diperoleh pemahaman yang mendalam tentang fenomena untuk selanjutnya dihasilkan sebuah teori.

Berikut tahapan-tahapan penelitian kualitatif yaitu:

1. Menemukan permasalahan

2. Melakukan studi literatur

3. Penetapan lokasi

4. Studi pendahuluan

5. Analisis data selama penelitian

6. Hasil, cerita, personal, deskripsi tebal, naratif Langkah-langkah yang digunakan untuk melakukan penelitian adalah:

1. Membaca secara menyeluruh Novel Sandiwara Langit karya Abu Umar Basyier cetakan kesepuluh

2. Mencatat hal-hal yang berhubungan dengan Tuhan atau ibadah yang dilakukan oleh 
tokoh, kemudian memberi kode atau tanda pada novel tersebut.

\section{HASIL DAN PEMBAHASAN}

Novel Sandiwara Langit, merupakan novel karangan Abu Umar Basyier cetakan kesepuluh. Novel ini menceritakan seorang remaja pengangguran bernama Rizqaan, Rizqaan yang belum punya pekerjaan ingin melamar Halimah.

la adalah pemuda shalih, yang berjuang keras menyelamatkan diri dari fitnah membujang, dengan segera menikah segala keterbatasan yang ada. Modal belum ada pekerjaanpun tak punya. Halimah pemudi yang juga shalihah, putri Pak Rozaq, seorang pengusaha kaya raya menjadi pilihannya. Meski dari keluarga apa adanya, sebagai muslim idealis, Rizqaan tak gentar menemui keluarga Halimah, untuk maju meminang. Terkesan nekat, tetapi begitulah selama itu adalah kebenaran yang diyakini, setelah melalui musyawarah yang ulet, akhirnya Rizqaan berhasil mendapatkan restu dari Pak Rozaq untuk menikahi Halimah. Namun dengan syarat yang cukup unik, yaitu apabila dalam waktu sepuluh tahun Rizqaan tidak bisa hidup makmur bersama Halimah, maka dia harus menceraikan Halimah dan mengembalikan Halimah kepada Rozaq.

Dari ringkasan tersebut, penulis mengambil inti untuk penulisan artikel ini yaitu nilai religius yang terdapat pada Novel Sandiwara Langit.Nilai berasal dari bahasa latin valere (berguna, mampu akan, berdaya, berlaku, kuat). Nilai adalah sesuatu yang penting atau hal-hal yang berguna bagi manusia atau kemanusiaan yang menjadi sumber ukuran dalam sebuah karya sastra. Nilai religius adalah nilai yang berhubungan langsung dengan Tuhan. Penulis memasukkan unsur tersebut agar dimanapun kita selalu diingatkan untuk tetap ingat kepada Tuhan.

Sastra sering memuat nilai-nilai religius. Hal ini terjadi karena pada awalnya semua sastra adalah religius. Istilah religius membawa konotasi pada makna agama. Religius dan agama memang erat berkaitan berdampingan bahkan melebur dalam suatu kesatuan, namun sebenarnya keduanya menyaran pada makna yang berbeda. Agama lebih menunjukkan pada kelembagaan kebaktian kepada Tuhan dengan hukum-hukum yang resmi. Religiositas di pihak lain, melihat aspek di lubuk hati, riak getaran nurani pribadi, totalitas kedalaman pribadi manusia. Dengan demikian, religius bersifat mengatasi, lebih dalam, dan lebih luas dari agama yang tampak, formal, dan resmi[5]. Seorang religius adalah orang yang mencoba memahami dan menghayati hidup dan kehidupan ini lebih dari sekedar lahiriah saja. Dia tidak terikat pada agama tertentu yang ada di dunia ini sehingga untuk indikator nilai religius adalah setiap perkataan dan perbuatan selalu berlandaskan ajaran Allah[6].

Dari keseluruhan jumlah nilai religius yang ditemukan sebanyak lima belas nilai, dengan indikator:

a. taat beribadah,

b. selalu mengingat Tuhan,

c. berserah diri pada Tuhan.

Sebelum penulis meneliti dalam penelitian ini, peneliti berpedoman kepada penelitian yang relevan. Maguna Eliastuti meneliti sebuah Novel Kembang Turikarya Budi Sardjono. Eliastuti meneliti unsur nilai-nilai moralyang terkandung dalam cerita dengan simpulan ada aspek positif dan aspek negatif pada tokoh utama dalam novel tersebut[7]. Begitu juga dengan Daruwati meneliti nilai-nilai pendidikan dalam Novel Sebelas Patriot karya Andrea Hirata. Daruwati menyimpulkan bahwa Nilai-nilai pendidikan yang terdapat dalam novel Sebelas Patriot karya Andrea Hirata antara lain[8]:

1. Nilai Patriotisme;

2. Nilai Moral;

3. Nilai Sosial;

4. Nilai Budaya.

Adapun fungsi nilai pendidikan antara lain:

1. Sebagai fungsi nilai budaya;

2. Sebagai fungsi nilai moral;

3. Sebagai fungsi nilai sosial.

Erlina juga melakukan penelitian terhadap unsur ekstrinsik yang terkandung dalam Novel Sang Pemimpi karya Andrea Hirata. Erlina menyimpulkan bahwa unsur ekstrinsik yang dapat dalam novel Sang Pemimpi karya Andrea Hirata adalah nilai pendidikan budaya, di mana budaya yang tercantum dalam novel Sang Pemimpi yaitu apabila sudah beranjak remaja maka sudah mulai bekerja untuk mencari uang. nilai pendidikan sosial, yaitu adanya sikap saling tolong menolong seperti Arai dan Mak Cik, dan seperti pendeta dan Jimbron. nilai pendidikan religius yaitu terlihat pada pendeta dan Jimbron, 
walaupun Jimbron diasuh oleh seorang pendeta, tetapi pendeta tersebut tidak memaksakan agamanya pada Jimbron. nilai pendidikan moral dan politik terlihat pada seorang pemimpin yang tidak mempunyai moral dan kejujuran.[9]

Berdasarkan penelitian Maguna Eliastuti, Daruwati, dan Erlina yang ketiganya sejalan dengan penelitian ini yaitu menganalisis nilainilai, kemudian penulis dalam artikel ini mengambil bagian dari nilai-nilai yaitu nilai religius atau agama.

Nilai religius merupakan nilai yang paling banyak ditemukan, nilai religius indikatornya taat beribadah dan selalu berhubungan dengan Tuhan. Rizqaan yang menjadi tokoh utama yang menjadi fokus dari penelitiandan istrinya Halimah dan yang terakhir tokoh ustadz, berikut beberapa nilai yang ditemukan:

"Mulailah dengan bismillah. Bertawakkallah kepada Allah, sebelum di saat dan sesudah kamu memulai usahamu setiap hari. Hanya kepada Allah saja hendaknya kamu beriman dan bertawakkal".

"Tetaplah berjalan di atas garis lurus ajaran syariat. Tawakkal selalu memberi kebaikan buat dirimu." [10]

Dari kutipan di atas tergambar seorang tokoh Rizqaan selalu melakukan atau mengerjakan sesuatu selalu berpedoman kepada agama yang dianutnya. Setiap apapun yang dikerjakan selalu mengingat Allah. Pada kutipan pertama disebutkan setiap pekerjaan yang dilakukan haruslah dimulai dengan bismillah seperti yang diajarkan oleh rasulullah terhadap umatnya. Pada kutipan kedua pengarang memberikan tuturan bagaimana kehidupan Rizqaan dari kecil sudah mengetahui akidah yang baik, Rizqaan tidak terpengaruh dengan duniawi, dan selalu berpegang teguh di jalan yang baik tanpa adanya pengaruh dari luar, selain itu penulis melalui firman Allah, semakin mempertegas ketaatan Rizqaan seorang sosok yang religius.

"Rizqaan seperti tumbuh menjadi remaja shalih, di lingkungan orang-orang yang kebanyakan jauh dari keshalihan. la mengenal masjid, saat remaja-remaja lain lebih akrab dengan bioskop, mall atau malah diskotik dan Night Club. la sudah akrab membuka lembaran-lembaran buku berbahasaArab, membaca tafsir dan mempelajari bacaan al-Quran secara tartil, saat anak-anak muda seusianya sibuk membaca komik-komik, cerpen dan novel percintaan Shackespeare, atau mendengar lagu-lagu pop terbaru yang disenandungkan oleh para biduan dan biduanita bersuara emas. la menjadi sosok remaja yang langka, yang dalam bahasa hadits disebut gharib, asing. Namun keterasingannya itulah yang membuatnya menjadi unik, dan karenanya saya tertarik mengajaknya menempuh jalan-jalan kemuliaan. Dari situlah, berbagi kisah nyata ini bermula, dan saya ikut menjadi saksi dari setiap desah keceriaan dan kesedihan di balik lembaran-lembarannya."

"Rizqaan teringat firman Allah: "Dan di antara tanda-tanda kekuasaan-Nya ialah dia menciptakan untukmu istri-istri dari jenismu sendiri supaya kamu cenderung dan merasa tenteram kepadanya, dan dijadikan-Nya di antaramu rasa kasih sayang. Sesungguhnya pada demikian itu benar-benar terdapat tanda-tanda bagi kaum yang berpikir." (Ar-Rum: 21) [10].

Dari kutipan di atas pengarang mempertegas sosok Rizqaan seorang anak sholeh, diceritakan dari kecil Rizqaan sudah belajar tentang agama dan memahaminya secara mendalam, sehingga tumbuh menjadi remaja yang alim. Di samping itu agar tidak terjadi suatu fitnah, Rizqaan sudah memutuskan untuk menikah ketika teman-teman seusianya masih menghabiskan masa mudanya bersenang-senang, Rizqaan lebih memilih untuk menikah dan memperdalam ilmu agama.

Selain Rizqaan, penulis juga menemukan nilai religius melalui tokoh Halimah, istri Rizqaan. Nilai tersebut terdapat pada kutipan berikut:

"Tidak begitu anakku sayang. Kalau mau masuk surga, kamu harus banyak beribadah. Harus rajin shalat, rajin membaca Al-Qur'an. Dan jangan lupa berbuat baik kepada kedua orang tuamu. Kamu harus jadi anak yang baik dan shalih."

"Untuk bisa berzakat, kita harus punya harta. Untuk bisa berhaji, kita perlu uang. Untuk bisa berinfak dan bersedekah, kita perlu memiliki sesuatu yang bisa diberikan kepada orang lain. Itulah kenapa nabi SAW bersabda, "orang yang berusaha membantu janda dan orang miskin adalah seperti orang yang berjihad di jalan Allah. Bahkan seperti orang mengerjakan shalat malam tanpa henti dan seperti orang yang tidak henti berpuasa."[10]

Dari kutipan tersebut dapat disimpulkan bahwa dalam kehidupannya, Halimah berpegang teguh pada agama dan selalu mengingat Tuhan, dalam mengajarkan agama kepada anaknya. Kemudian tokoh terakhir yaitu ustadz panutan Rizqaan, dalam novel nama ustdznya tidak disebutkan, namun nilai religius terdapat pada kutipan berikut:

"Kalau begitu lakukanlah. Tapi tetaplah lakukan istikarah. Ulangi terus hingga berkali-kali, sampai 
kamu yakin bahwa Allah telah memberikan jalan terbaik bagimu".

"Syaikh Abdullah bin Jarillah menjelaskan"Allah juga mewajibkan kepada suami untuk menafkahi istrinya. Itu juga merupakan kompensasi karena wanita akan lebih banyak tinggal di dalam rumah, berkonsentrasi penuh membina rumah tangga. Itu menunjukkan kasih saying lain, yang Allah berikan kepada wanita. Kesimpulannya, bahwa mahar seorang wanita haram untuk dimakan orang lain (termasuk oleh suaminya), bahkan dianggap harta busuk dan hina, dan perbuatan itu dianggap tindakan dzhalim dan kemungkaran."

Ustadz teringat sabda Rasulullah, "seorang istri harus mendapatkan makan sebagaimana kalian makan, mendapatkan pakaian sebagaimana yang kalian kenakan. Jangan sekali-kali memukul wajahnya, jangan menjelek-jelekkan, serta jangan memisahkan dirinya dengan kalian kecuali hanya di dalam rumah saja."[10]

Kutipan tersebut memperlihatkan seorang ustadz yang selalu menganjurkan shalat atau beribadah diwaktu tengah malam untuk menyelesaikan masalah yang tujuannya untuk berserah diri kepada Allah Swt agar mendapatkan ketenangan diri. Kemudian penulis menguatkan tokoh ustadz dengan menambahkan pesan dari Rasulullah Saw.

Dari kutipan tersebut dapat disimpulkan apapun yang dilakukan oleh para tokoh selalu berpegang teguh terhadap agamanya, karena setiap aktivitas yang dilakukan selalu berpedoman kepada agama. Semua hal yang dimaksudkan agar setiap umatNya selamat dalam menjalani menjalani kehidupan di dunia dan mampu menggapai tempat yang terindah nantinya (surga). Hendaknya kita semua mematuhi perintah dan menjauhi laranganNya.

\section{SIMPULAN}

Dari hasil penelitian yang telah penulis lakukan maka dapat penulis dapat memberikan simpulan bahwa dalam Novel Sandiwara Langit banyak ditemukan nilai religius dari tokoh yang bernama Rizqaan, apapun kegiatan yang dilakukan oleh Rizqaan, selalu mengerjakannya sesuai dengan agama dan kepercayaan yang dianutnya, sehingga menyarankan kepada pembaca untuk tetap berpegang teguh terhadap keyakinan yang dianut oleh pembaca.

\section{DAFTAR PUSTAKA}

[1] Taum, Yoseph Yapi. (1997). Pengantar Teori Sastra. Flores; Nusa Indah.

[2] Musthafa, Bachrudin. (2008). Teori dan
Praktik Sastra dalam Penelitian dan Pengajaran. Jakarta; Cahaya Insan Sejahtera.

[3] D. M. A. Lexy J. Moleong, (2019). Metodologi Penelitian Kualitatif (Edisi Revisi), PT. Remaja Rosda Karya, doi: 10.1016/j.carbpol.2013.02.055.

[4] N. Alfianika,(2018).Metode Penelitian Pengajaran Bahasa Indonesia. Yogyakarta; Deepublish.

[5] Z. Taufik, (2017). Revitalisasi Dan Variasi Sufisme Kontemporer Di Perkotaan: Studi atas Sufisme Perennial Padepokan Thaha Jakarta.Dialekt. J. Islam. Stud. Local Cult. Stud.

[6] M. Qomar, (2019). Penelusuran PrototipePemikiran IslamFaisal Ismaildan Problem yang Menghadang. Nun J. Stud. Alquran dan Tafsir di Nusant. doi: 10.32495/nun.v4i1.41.

[7] M. Eliastuti, (2017). Analisis Nilai-Nilai Moral dalam Novel 'Kembang Turi Karya Budi Sardjono.J. Genta Mulia.

[8] Daruwati, (2013). Analisis Struktur Dan Nilai-Nilai Pendidikan Dalam Novel Sebelas Patriot Karya Andrea Hirata. Progr. Stud. Pendidik. Bhs. Dan Sastra Indones. Fak. Kegur. Dan Ilmu Pendidik. Univ. Widya Dharma Klaten. doi: 10.1017/CBO9781107415324.004.

[9] E. Erlina,(2017).AnalisisUnsur EkstrinsikNovel Sang PemimpiKarya Andrea Hirata.J. KATA, 2017, doi: 10.22216/jk.v1i2.2301.

[10] Basyier, Abu Umar. (2011). Sandiwara Langit Cetakan Kesepuluh. Jakarta; Shafa Publika.

\section{Profil Penulis}

Megi Afroka adalah Dosen Tetap di Akademi Manajemen Informatika dan Komputer Kosgoro Solok yang mangajar mata kuliah Bahasa Indonesia. Penulis dilahirkan di Cupak Kabupaten Solok Sumatera Barat pada tanggal 28 Agustus 1986. Sarjana Pendidikan Guru Sekolah Dasar diselesaikan di Universitas Terbuka pada Tahun 2012 dan Megister Pendidikan diselesaikan di Universitas Bung Hatta pada tahun 2016. 